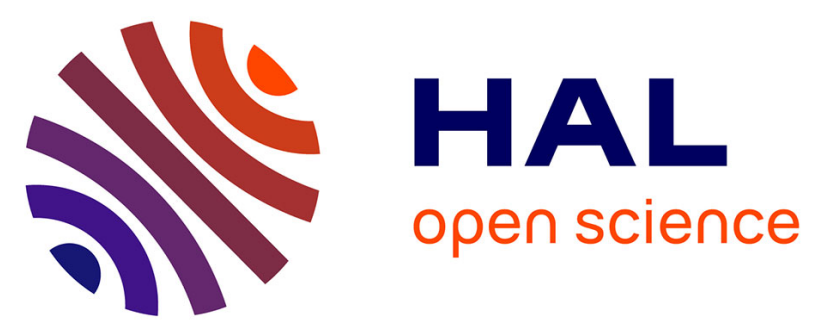

\title{
A small-scale randomized controlled trial of the revised new forest parenting programme for preschoolers with attention deficit hyperactivity disorder
}

\author{
Margaret J. J. Thompson, Cathy Laver-Bradbury, Michelle Ayres, Emma \\ Poidevin, Sarah Mead, Catherine Dodds, Lamprini Psychogiou, Paraskevi \\ Bitsakou, David Daley, Anne Weeks, et al.
}

\section{To cite this version:}

Margaret J. J. Thompson, Cathy Laver-Bradbury, Michelle Ayres, Emma Poidevin, Sarah Mead, et al.. A small-scale randomized controlled trial of the revised new forest parenting programme for preschoolers with attention deficit hyperactivity disorder. European Child and Adolescent Psychiatry, 2009, 18 (10), pp.605-616. 10.1007/s00787-009-0020-0 . hal-00535146

\author{
HAL Id: hal-00535146 \\ https://hal.science/hal-00535146
}

Submitted on 11 Nov 2010

HAL is a multi-disciplinary open access archive for the deposit and dissemination of scientific research documents, whether they are published or not. The documents may come from teaching and research institutions in France or abroad, or from public or private research centers.
L'archive ouverte pluridisciplinaire HAL, est destinée au dépôt et à la diffusion de documents scientifiques de niveau recherche, publiés ou non, émanant des établissements d'enseignement et de recherche français ou étrangers, des laboratoires publics ou privés. 


\title{
A small-scale randomized controlled trial of the revised new forest parenting programme for preschoolers with attention deficit hyperactivity disorder
}

\author{
Margaret J. J. Thompson · Cathy Laver-Bradbury $\cdot$ Michelle Ayres · Emma Le Poidevin · Sarah Mead · \\ Catherine Dodds · Lamprini Psychogiou • Paraskevi Bitsakou • David Daley • Anne Weeks • \\ Laurie Miller Brotman · Howard Abikoff · Penny Thompson · Edmund J. S. Sonuga-Barke
}

Received: 5 September 2008/ Accepted: 26 March 2009/Published online: 30 April 2009

(c) Springer-Verlag 2009

\begin{abstract}
The revised new forest parenting programme (NFPP) is an 8-week psychological intervention designed to treat ADHD in preschool children by targeting, amongst other things, both underlying impairments in self-regulation and the quality of mother-child interactions. Forty-one children were randomized to either the revised NFPP or treatment as usual conditions. Outcomes were ADHD and
\end{abstract}

M. J. J. Thompson $(\bowtie) \cdot$ C. Dodds · L. Psychogiou ·

P. Bitsakou - E. J. S. Sonuga-Barke

School of Psychology, Institute for Disorders of Impulse

and Attention, University of Southampton,

Southampton SO17 1BJ, UK

e-mail: mt1@soton.ac.uk; ejb3@soton.ac.uk

C. Laver-Bradbury

School of Nursing, University of Southampton,

Southampton, UK

M. J. J. Thompson - C. Laver-Bradbury · A. Weeks

Child and Adolescent Mental Health Service,

Southampton City PCT, Southampton, UK

M. Ayres · E. Le Poidevin - S. Mead · P. Thompson

Child and Adolescent Mental Health Service, Guernsey, UK

D. Daley

School of Psychology, Bangor University, North Wales, UK

L. M. Brotman · H. Abikoff

Child Study Center, New York University School of Medicine,

New York, USA

E. J. S. Sonuga-Barke

Social, Genetic, Developmental Psychiatry Centre,

Institute of Psychiatry, London, UK

E. J. S. Sonuga-Barke

Department of Experimental Clinical and Health Psychology,

Ghent University, Ghent, Belgium
ODD symptoms measured using questionnaires and direct observation, mothers' mental health and the quality of mother-child interactions. Effects of the revised NFPP on ADHD symptoms were large (effect size $>1$ ) and significant and effects persisted for 9 weeks post-intervention. Effects on ODD symptoms were less marked. There were no improvements in maternal mental health or parenting behavior during mother-child interaction although there was a drop in mothers' negative and an increase in their positive comments during a 5-min speech sample. The small-scale trial, although limited in power and generalizability, provides support for the efficacy of the revised NFPP. The findings need to be replicated in a larger more diverse sample.

Keywords Preschool - ADHD - New forest parenting programme $\cdot$ Psychosocial treatments $\cdot$ Parent training

\section{Introduction}

In the past decade there has been a marked increased use of psycho-stimulants for the treatment of attention deficit hyperactive disorder (ADHD) in preschool children [41]. However, a recent randomized trial highlighted various limitations of stimulants as a treatment in this age group. Efficacy was more limited than in school-age children [12] and there were significant levels of side effects [19]. A substantial minority of parents were reluctant to place their children on medication [40]. These factors, combined with the more general concern amongst parents and clinicians about using stimulants with young children makes empirical testing of non-pharmacological treatments for ADHD preschoolers a public health priority. Unfortunately, psychosocial treatments for ADHD have in general been less 
effective than medication in terms of the control of core symptoms of the disorder in clinically diagnosed samples [14]. For instance, the multi-modal treatment of ADHD (MTA) study compared medication and psycho-social approaches to the treatment of ADHD over 14 months in a randomized controlled trial. The psycho-social arm was very intensive and included substantial parent-based, school-based, and child-focused elements. Disappointingly, children in this arm, while showing significant reductions in ADHD symptoms over the course of the trial, fared no better than those in a community control condition and significantly worse than those in a 'medication only' arm. Furthermore, the combination of psycho-social treatment and medication was no more effective in reducing ADHD symptoms than medication alone [16, 38]. The MTA study does support the use of psycho-social approaches with ADHD children as a way of reducing oppositional and noncompliant behavior [7]. The value of such approaches for the treatment of oppositional behavior is confirmed by trials of parent training interventions developed for noncompliant children based on generic behavior modification principles such as Incredible Years [39] and Triple P [21]. These have also been shown to be effective in reducing oppositional behavior in ADHD children [2, 17]. Consistent with this picture a recent study in a Dutch sample found effects of generic parent training on both internalizing and general behavior problems but not ADHD symptoms [37]. Where studies have shown positive effects of parent training on ADHD symptoms these have typically included children who have general patterns of disruptive behavior disorders including children with raised levels of ADHD symptoms, but who do not have a rigorous diagnosis of ADHD [17]. One reason why such approaches may not be optimal with regard to ADHD as a treatment target is that they are based on generic approaches designed to reduce difficult behaviors which are adapted to for ADHD populations [9] rather than being developed specifically to target ADHD behaviors or the psychological deficits thought to underlie them (e.g., executive dysfunction; [31]).

The new forest parenting programme (NFPP) was initially developed as a specialized psychological intervention for preschool children with ADHD [32]. In a randomized controlled trial [30], NFPP was shown to be superior to both active and wait list control conditions in reducing ADHD and oppositional defiant disorder (ODD) symptoms in 3 years. Furthermore effects persisted up to 15 weeks after the end of the intervention. The effect size for ADHD symptoms (ES $=0.87 ; 53 \%$ normalization) was within the range found with stimulants in preschoolers [34]. Furthermore, NFPP increased the levels of positive parenting and reduced mental health problems. In this first trial, the intervention was implemented by highly motivated and trained health visitors with experience in childhood behavior problems working from a child mental health centre. Unfortunately, these positive findings were not replicated in a trial of the treatment delivered in a more standard community setting using randomly selected nonspecialist health visitors who had less intensive clinical supervision than in the previous trial and for some, as they saw fewer families, less practice at the program [27].

The ultimate goal of this program is to deliver an intervention to achieve long-lasting reductions of core symptoms at home and also in school and other functional settings. Accordingly, the NFPP was revised in an attempt to work toward this goal. A key aspect of the revision was a focus on underlying deficits hypothesized to cause ADHD [31]. We relied on the primary caregiver to carry out activities and exercises intended to enhance certain regulatory skills. We posited that reliance on the parent as the agent-of-change and focus on core deficits in self-regulation would lead to maintenance of effects over time and generalization across settings. We also aimed to strengthen and formalize and make explicit the theoretical foundations of the intervention. This involved developing the concept of constructive parenting - whereby a parent acts as an 'engine' for the development of their child's self-regulatory and self control.

The revised program has a number of features that make it distinctive from other non-pharmacological interventions. Figure 1 outlines the goals of the revised NFPP along with some key issues in implementation. Many of the elements of the program were fully present in the original NFPP, some elements implicit in the original are now made explicit and given a more formal theoretical basis in the new version of the program (see [32] for a description of the core goals of the revised NFPP). Other elements are completely novel. As in the original NFPP the program is specifically designed for preschool-age children. We have argued elsewhere that the early preschool years may be optimal for psycho-social ADHD interventions for a number of reasons [32]. The brain is likely to be more plastic; there may be less complications and comorbidities to create barriers to change than is the case with older ADHD children; parental negative reactions are less likely to be so hardened toward their challenging ADHD children than may be the case later on in development; there has been a limited time for ADHD children's behavioral patterns to be reinforced by their environment. Crucially, the ADHD syndrome appears to have similar levels of validity in the preschool and school periods in terms of the way the core features cluster together, can be distinguished from other related and overlapping problems such as oppositional behavior and non-compliance and predict continued disorder and impairment [10].

The program was delivered in the child's home during eight weekly visits by a trained clinician. A home-based 


\begin{tabular}{|c|c|c|c|c|c|c|c|c|c|}
\hline \multirow[t]{2}{*}{ GENERAL GOALS } & \multirow[t]{2}{*}{ TREATMENT TARGETS } & \multicolumn{2}{|c|}{ PSYCHOEDUCATION } & \multicolumn{2}{|c|}{$\begin{array}{l}\text { PARENT-CHILD } \\
\text { PLAY }\end{array}$} & \multirow{2}{*}{$\begin{array}{l}\text { MAJOR } \\
\text { REVIEW } \\
\text { Week } 5 \\
P \\
\text { Feedback } \\
\text { on session } \\
\end{array}$} & \multicolumn{2}{|c|}{$\begin{array}{l}\text { PARENT-CHILD } \\
\text { TASK }\end{array}$} & \multirow{2}{*}{$\begin{array}{c}\text { FINAL } \\
\text { REVIEW } \\
\text { Week } 8 \\
P \\
\text { Review diaries/ } \\
\text { checklists. }\end{array}$} \\
\hline & & $\begin{array}{c}\text { Week } 1 \\
P\end{array}$ & $\begin{array}{c}\text { Week } 2 \\
P\end{array}$ & $\begin{array}{l}\text { Week } 3 \\
P \& C\end{array}$ & $\begin{array}{l}\text { Week } 4 \\
P \& C \\
\text { Video } \\
\text { session }\end{array}$ & & $\begin{array}{l}\text { Week } 6 \\
P \& C \\
\text { Video } \\
\text { session }\end{array}$ & $\begin{array}{l}\text { Week } 7 \\
P \& C \\
\text { Feedback } \\
\text { on session }\end{array}$ & \\
\hline $\begin{array}{l}\text { IMPROVE } \\
\text { PARENTAL STYLE }\end{array}$ & $\begin{array}{cl}\text { P to be - } \\
\text { - understanding } \\
\text { - } \\
\text { - } \text { ponstructive } \\
\text { - } \text { organised }\end{array}$ & \multicolumn{2}{|c|}{$\begin{array}{l}\text { Assess/engage } \mathrm{P} \text {; build up C- } \\
\mathrm{P} \text { relationship } \\
\text { Psycho-education about } \\
\text { ADHD }\end{array}$} & \multicolumn{2}{|c|}{$\begin{array}{l}\text { Link C } \\
\text { behaviour with } \\
\text { ADHD concept. } \\
\text { Match programme } \\
\text { to P \& C needs. }\end{array}$} & \multirow{3}{*}{$\begin{array}{l}\text { Review/ } \\
\text { strengthen } \\
\text { key } \\
\text { messages } \\
\text { in areas of } \\
\text { continuing } \\
\text { weakness. }\end{array}$} & \multirow{4}{*}{\multicolumn{2}{|c|}{$\begin{array}{l}\text { Continue with the } \\
\text { concepts } \\
\text { introduced earlier using } \\
\text { different techniques } \\
\text { adapted to needs of P } \\
\text { \& C. }\end{array}$}} & \multirow{4}{*}{$\begin{array}{l}\text { Overall review } \\
\text { of progress - } \\
\text { highlighting } \\
\text { achievements } \\
\text { and identify } \\
\text { continuing } \\
\text { areas of } \\
\text { weakness. } \\
\text { Developing } \\
\text { tailored } \\
\text { continuation } \\
\text { strategy in each } \\
\text { domain. }\end{array}$} \\
\hline $\begin{array}{l}\text { HELP } \\
\text { PARENTS } \\
\text { COMMUNICATE }\end{array}$ & $\begin{array}{cl}\text { P to - } & \\
- & \text { listen } \\
- & \text { be authoratative } \\
- & \text { be clear } \\
\text { - } & \text { be consistent }\end{array}$ & \multicolumn{2}{|c|}{$\begin{array}{l}\text { Work on communication, } \\
\text { eye contact, short sentences } \\
\text { Praise }\end{array}$} & \multicolumn{2}{|c|}{$\begin{array}{l}\text { Extend use of } \\
\text { teachable moments } \\
\text { within the session. } \\
\text { Brain storming and } \\
\text { modelling }\end{array}$} & & & & \\
\hline $\begin{array}{l}\text { IMPROVE } \\
\text { MANAGEMENT } \\
\text { OF ODD }\end{array}$ & $\begin{array}{cl}\text { P to learn - } \\
\qquad \quad \text { behaviour principles } \\
-\quad \text { preventative } \\
\text { - } \\
\text { strategies } \\
\text { Contingencies }\end{array}$ & \multicolumn{2}{|c|}{$\begin{array}{l}\text { Work on - } \\
\text { - } \quad \text { keeping calm } \\
\text { - giving choices }\end{array}$} & \multicolumn{2}{|c|}{$\begin{array}{l}\text { Importance of pro- } \\
\text { activity. } \\
\text { rules/boundaries. } \\
\text { behaviour charts } \\
\text { quiet time/time out } \\
\text { (week 4) }\end{array}$} & & & & \\
\hline $\begin{array}{l}\text { IMPROVE } \\
\text { REGULATION } \\
\text { THROUGH } \\
\text { INTERACTION } \\
\text { AND GAMES }\end{array}$ & $\begin{array}{c}\text { P to improve - } \\
\text { - } \quad \text { joint play/ } \\
\text { - } \quad \text { surn taking } \\
\text { - } \quad \text { C selff regulation. }\end{array}$ & \multicolumn{2}{|c|}{$\begin{array}{l}\text { Introduce scaffolding } \\
\text { concept. } \\
\text { Bring in homework. } \\
\text { Introduce teachable } \\
\text { moments/training games } \\
\text { (week 2). }\end{array}$} & \multicolumn{2}{|c|}{$\begin{array}{l}\text { Fun play and } \\
\text { development of } \\
\text { language } \\
\text { and self control. } \\
\text { Review games } \\
\text { progress/ adjust } \\
\text { targets. }\end{array}$} & $\begin{array}{l}\text { Increase } \\
\text { difficulty of } \\
\text { games/ } \\
\text { review } \\
\text { teachable } \\
\text { moments }\end{array}$ & & & \\
\hline
\end{tabular}

Fig. 1 The structure of the revised New Forest Parenting Program highlighting treatment goals and targets and the therapeutic context across the 8 weeks of the program. $P$ parent, $C$ child

approach enables the therapist to use everyday materials and situations to demonstrate and apply parenting strategies. Intervention in the home may aid in generalization across situations and over time. Other elements that are found in both the original and revised versions are, the focus on improving the quality of the mother-child relationship to increase positive parenting, and second, the use of standard behavioral approaches to target non-compliance and oppositional behavior. Further as in the original NFPP, the therapists are trained to pace the intervention to respond to the mental health needs of the parent. For instance parental depression or ADHD can be barriers to successful parent training [23, 28].

The novel aspects of the revised program extend standard social learning-based approaches to behavior management found in other interventions for ADHD by including new therapeutic elements based on developmental models of social and cognitive development. This focuses on the need to develop constructive and reciprocal interaction between mother and child through which the child's self-regulatory skills are developed and extended. We define constructive parenting as a dynamic process by which parents; (1) scope their children's self-regulatory abilities to establish their existing level of competence, (2) work within this level of competence (i.e., their zone of proximal development) to set realistic but challenging goals, (3) provide the support and motivation and developmental scaffolding to allow the child to reach these goals, (4) identify when these goals have been met and (5) rescope and set new goals. This core therapeutic element is supplemented in the revised NFPP by increased work on parental communication style and the extension of language skills in the child [18].

Implementation of these novel elements of the revised NFPP rely on the parent taking the role of the child's 'selfregulation trainer' to promote psychological growth and the acquisition of competencies. Fundamental to this training approach is the use of games that the mother engages in with the child to help him attend, concentrate, take turns, enhance working memory and learn to wait. The therapist also uses situations that occur naturally in the home as opportunities to model effective interactions with the child so that the parent can copy these behaviors herself. In so doing, the parent learns to identify and expose the child to numerous real-world situations that call for the use of the regulatory skills being taught (i.e., teachable moments). This naturalistic behavioral teaching approach, which has been used successfully in treatment programs with autistic children [25], provides numerous opportunities for generalization, a central concern and goal in the behavioral treatment of children with ADHD. To enhance this approach in the revised version, two sessions are filmed by the therapist and played back to the parent emphasizing the positive aspects of the mother-child 
interaction. The revised version also places greater emphasis on flexible delivery of treatment (within the constraints of the manual) in order to adapt to the particular needs of the carer(s) and child.

In this paper, we present the results from an initial small-scale randomized controlled trial of the revised NFPP. Our primary aim was to examine feasibility and acceptability and to estimate the efficacy of the program against a referral and treatment as usual control group (TAU) in reducing children's ADHD symptoms. A secondary aim was to examine therapeutic effects on the quality of mother-child interaction and mother's mental health (i.e., depression and ADHD symptoms).

\section{Method}

The project received Ethical Approval by the Guernsey Health and Social Services Department and School of Psychology at the University of Southampton.

\section{Recruitment and participants}

Forty-one children ( 31 boys) between the ages of 30 and 77 months meeting study criteria for ADHD entered the trial. Children were recruited over an 18-month period via local child and family health clinics and by advertisements placed in the local press targeting the total population of the island of Guernsey (approximately 686 births a year). We recruited over a wider age range than the previous trial [30] due to the limited recruitment period we had, and the birth rate in Guernsey. There was a three stage screening process.

\section{Stage 1: questionnaire screen}

Seventy-seven mothers were screened initially during the recruitment phase. These mothers completed the WerryWeiss-Peters-Hyperactivity Scale (WWP [26]). This questionnaire gives a single overall rating of activity problem symptoms displayed by preschool-aged children at home or while shopping. Seventy-four were identified for further assessment on the basis of a score of 14 or more on this instrument [26]. This threshold was set relatively low (i.e., equivalent to approximately the top $30 \%$ of the population [36]) so as to avoid excluding potential cases at the first stage of screening.

\section{Stage 2: parental concern over impairment}

Only parents who were concerned about their children's ADHD behavior were recruited. Nineteen children dropped out of the assessment process or were excluded at this stage (three were too old; one was not from Guernsey; two had had previous attendance at Child and Adolescent Mental Health Services; one was a sibling of a child already in the study; one child was found to be autistic); ten decided not to proceed further with the project, and one family could not be contacted). Concern about impairment was not assessed in any standardized way but was communicated during questioning at the initial assessments.

\section{Stage 3: clinical interview}

Remaining parents $(N=55)$ were administered an interview-the preschool version of the parental account of childhood symptoms (PACS). This is a structured clinical interview in which parents describe the presence or absence of ADHD and ODD symptoms over the last 6 months across a range of situations and includes a frequency and severity rating $[8,35]$. Although the PACS can be used to derive a DSM-IV diagnosis in older children a formal diagnosis was not made in the current trial as the PACS diagnosis has not been validated for preschool children. Inclusion into the trial was a score of 16 or over on the PACS ADHD symptom scale. Nine children did not meet clinical criteria according to the PACS interview. Because of limited resources IQ was not assessed during the trial. Five families decided at this stage to go no further (before randomization). Forty-one families entered the trial and were randomized. Figure 2 provides a flow chart showing recruitment, randomization and patterns of drop out from the study. No child entering the trial had been on medication. No child received medication during the trial or the follow-up period. In addition families had to be fluent in English; able to commit to the length of the trial including the follow-up period, and were willing to be seen at home. Families were excluded from the trial if they had previously or were currently attending the local child and adolescent services, if the mother was known to have a severe mental illness or if the child had a pervasive developmental disorder, severe receptive language impairment, neurological disorder or was on the social services register for a current history of child sexual or physical abuse. The information about exclusion criteria was obtained directly from the mother and/or the referral source (e.g., health visitor). Families were not referred in or accepted following initial enquiries if they met exclusion criteria.

\section{Trial design}

Participants were randomized (using random number tables) to receive either the revised NFPP $(N=21)$ or TAU $(N=20)$ condition. Outcome measures were collected before treatment (T1), after treatment (week 9; T2) and then at (week 17; T3) for both arms of the trial. 
Fig. 2 Flowchart showing the number of patients entering each stage of the trial from initial screen to $\mathrm{T} 3$

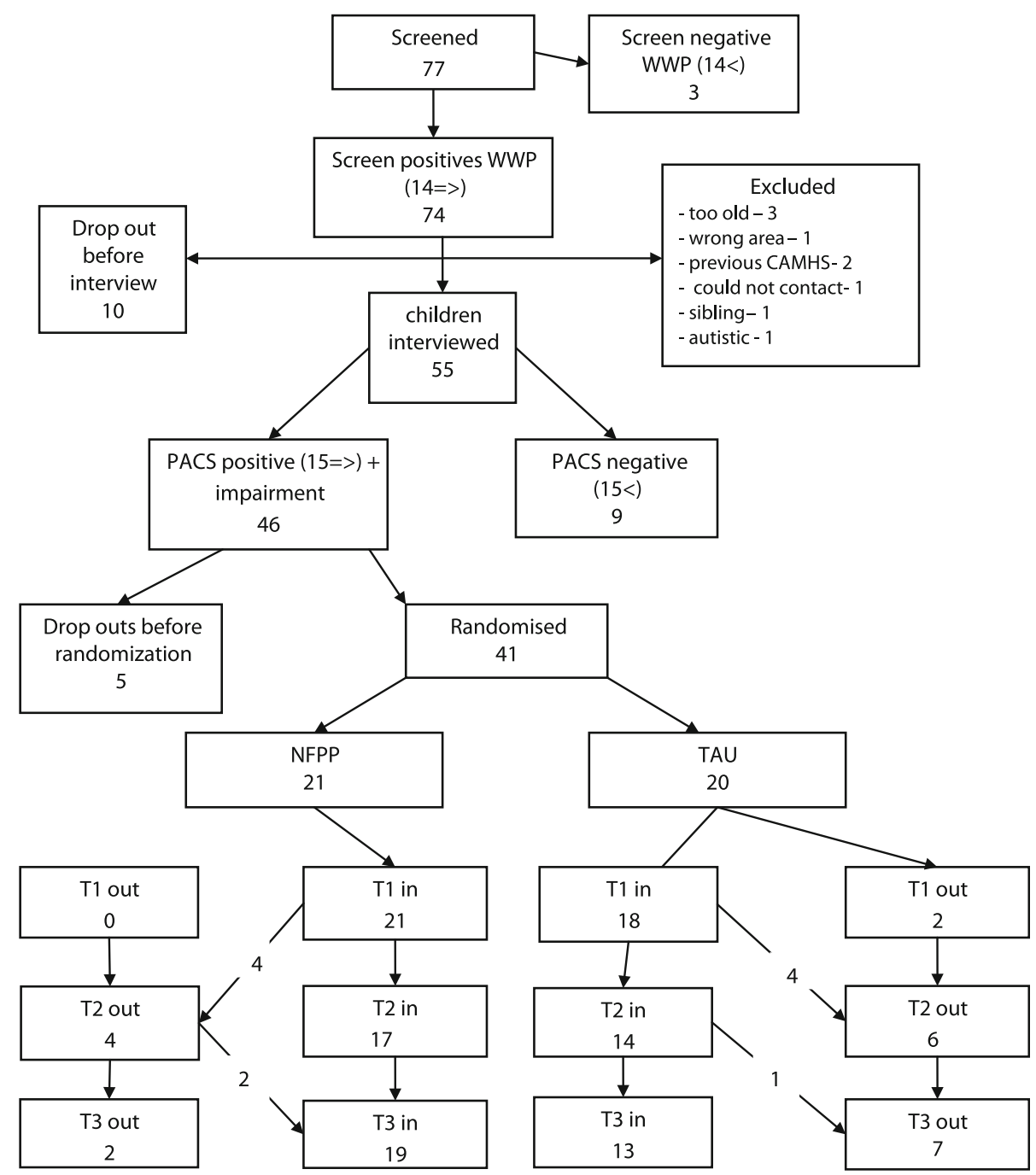

Treatment conditions

NFPP

Two part-time nurses were employed to deliver the intervention and were trained in the revised NFPP program by the first and second authors (MJJT and CL-B) who were core members of the program development team. Weekly telephone and email supervision was supported with monthly visits to supervise the therapists on a face-to-face basis for the first 6 months and then every 2 months for the last 7 months during the intervention phase. All therapy sessions were audio-taped and these tapes were used for supervision sessions to ensure that the intervention was delivered as planned. The integrity of ongoing treatment delivery was reviewed using checklists completed by the therapists and the clinical supervisors independently. The therapists also kept reflective diaries. The reflective diaries were used by the therapists to review the sessions and give a view on whether the families were responding to the program and to help plan the delivery of the following week

\section{Treatment as usual}

Treatment as usual was intended to control for the effects of time in treatment and to compare NFPP treatment effects with the potential impact of interventions typically provided by community-based practitioners on children's and parents' functioning during the course of treatment and follow-up. TAU participants received no treatment from study staff, nor were they referred onto services, but were given contact information for Health Visitors, general practitioners or school nurses which they could use as they wished. No TAU cases received any interventions for ADHD during the period of the trial, nor attended parenting programs: given this the TAU group functioned as a no treatment control group to all intents and purposes. TAU scores between T1 and T2 were also used for testretest reliability. All the families in the TAU group were 
offered therapy at the end of the study period if they wished.

\section{Assessment schedule}

The assessment schedule was identical for both conditions. All measures of child symptoms and functioning, maternal mental health and mother-child interactions were collected T1 through T3 by the research psychologist at the family home. Every effort was made to keep the assessing psychologist blind to the treatment status of the children. The therapists and the families were told not to discuss their treatment status with the psychologist. The psychologist was not aware of the therapy content delivered to the families and worked in a different part of the building from the therapists. The videos were coded after collection at a later time. The psychologist collecting the data coded it from only $\mathrm{T} 1$ sessions, T2 and T3 sessions were recorded by independent observers. Measures of inter-rater reliability were calculated on the basis of $31 \%$ of tapes across all time points by two independent raters blind to treatment status.

\section{Outcome measures}

\section{Child ADHD and oppositional and non-compliant behavior}

Parent reports The WWP Scale [26] and the preschool PACS [35] used as the screening questionnaires were also used to provide the ADHD outcomes. Both scales have been shown to have strong psychometric properties [26, 35]. The PACS has test-retest reliability of 0.83 and has been validated against direct measures of symptoms [30]. Inter-rater reliability of PACS in a sample of children with ADHD has been found to be satisfactory (ranging from 0.79 to 0.96 ) and has been found to correlate with teacher and parent rating scales of ADHD (0.68 and 0.78, respectively [5]). The WWP has test-retest reliability of 0.85 in the current study and is predictive of the clinical diagnosis [33]. The PACS social problems scale (oppositional noncompliant behavior) and the five-item scale the social problems scale (temper tantrums, difficult to manage, irritable, poor relationship with siblings, poor relationships with other children) from the Behavior Check List (a behavior measure for young children with adequate psychometric properties) were used to look also at oppositional non-compliant behavior. The BCL items have been shown to constitute a factor independent of other preschool problems (including hyperactivity) in a factor analysis of the BCL [24, 29]. In the current study test-retest reliability of these scales was adequate (PACS; 0.52; BCL; 0.54).

Direct observation of child overactivity and inattention The child was asked to play alone with a standard toy (a Farm Yard) for $5 \mathrm{~min}$ by his mother. This measure was used to assess the level of overactivity and inattention of the child. The child's ADHD-related behaviors were assessed on four items: time off-task, fidgets with body, fidgets with objects, and squirming, with higher scores indicating better attention and less activity. Scores ranged from 1 (not at all) to 5 (extremely often). The measures shows good inter-rater reliability with intra-class correlations for the child's ADHD Observation (31\% of the tapes $)=0.91$ ). The test-retest reliability of this measure was adequate at 0.48 .

\section{Parent measures}

\section{Parental ADHD}

The adult ADHD rating scale (AARS) [1] was used to assess adult ADHD symptoms. This is an 18-item selfreport scale based on the DSM-IV definition of symptoms of ADHD rated over the past 6 months on a 4-point scale, ranging from (0 Rarely) to (3 Very often). It has good psychometric properties and has been shown to be correlated with spousal, parental and cohabiting partner ratings of symptoms [1]. In the current study the internal consistency was satisfactory $(\alpha=0.91)$. A score of nine symptoms or more has been shown to identify adults with a clinical level of difficulty [20]. Test-rest reliability was 0.80 .

\section{Parental depressed mood}

The general health questionnaire (GHQ12) a widely used, reliable and well-validated questionnaire, was used to assess parental depressed mood. The scores from the 12 items are combined to produce an overall rating. Individuals respond on a 4-point anchored scale, scored 0 (better than usual; 0 same as usual; 1 less than usual; -1 much less than usual) [11]. In the current study the internal consistency was satisfactory $(\alpha=0.91)$. The GHQ has previously been shown to have good test-retest reliability ( $r=0.84$ [22]; in this study the figure was 0.43 ) and to be predictive of the diagnosis of clinical depression [13].

\section{Parental expressed emotion}

This was measured using the pre-school 5-min speech sample (PFMSS) of expressed emotion [8] and assesses the emotional climate of the mother-child relationship. The task yields four global ratings: initial statement, relationship, warmth, and emotional over-involvement as well as frequency counts of critical comments and positive comments. The PFMSS demonstrates good code-recode and inter-rater reliability, and adequate test-retest reliability 
and validity [8]. For each component of EE in this study, the inter-rater reliability was high: initial statement $(r=0.88)$; warmth $(r=0.77)$; relationship $(r=0.84)$; positive comments $(r=0.81)$; and negative comments $(r=0.77)$. The measure has also been previously shown to discriminate between the parents of preschool ADHD and non-ADHD children [8].

\section{Direct observation of mother-child interactions}

Three tasks were used to measure mother-child interaction

1. The mother was asked to play together with her child on the farm yard as she would normally play for $5 \mathrm{~min}$.

2. The mother was then asked to complete a jigsaw puzzle with her child for $5 \mathrm{~min}$. Her instructions were to choose one of several puzzles (brought by the therapist), which she thought would be developmentally appropriate for her child. She was instructed to help the child complete it by helping, but not do it for him.

3. Finally the mother was to ask her child to tidy all the toys away. The mother was asked to let the child do it but to help if necessary to enable the child to comply. The child had 5 min to complete the task.

This 15-min parent-child interaction was videotaped and coded at a later time using the global impressions of parent-child interactions-revised (GIPCI-R) (3). The GIPCI generates summary global ratings (1-5) for parent and child behaviors-the higher the score the more positive the outcome. Child items rated were; respect, destruction, disruptive, non-compliance, social skills, valance, disconnection. Parent ratings were valence, responsiveness, warmth, praise, enjoyment, scaffolding, effectiveness, aggression and criticism/punishment. In previous work with high-risk preschool-age children, Brotman et al. [3, 4] reported adequate inter-rater reliability for the individual codes in the original GIPCI. Global ratings have been shown to be significantly related to behavioral counts of behaviors during the same interactions, and parenting constructs based on GIPCI global ratings have been shown to be sensitive to intervention effects $[3,4]$. Using interclass correlations the average inter-rater reliability across all item codes in this study was adequate for child (intraclass correlation $=0.62$; range $0.48-0.77$ ) and parent (0.64; range $0.48-0.79)$. There was also good internal consistency of scales; $\alpha=0.86 ; \alpha=0.87$. Test-retest reliability was adequate for the parent measure $(r=0.50)$ but low for the child measure $(r=0.20)$.

Analytical approach Given the small-scale nature of the trial and the high rate of drop at T2 and T3 (see below) we decided that an intention to treat analysis, where we imputed data for non-completers, was not viable and could be potentially misleading. We therefore included only cases that had data at all three time points in the primary analysis. We used repeated measures analysis of covariance to test for the effects of treatment with the T2 and T3 scores for each outcome variable as the dependent variable, treatment group as the independent variables and $\mathrm{T} 1$ scores as the covariate. The between subject factor was group and the within subject factor was time (change between $\mathrm{T} 2$ and T3). The interaction between these two factors would therefore indicate a change in the effect of the intervention between $\mathrm{T} 2$ and follow-up at T3. The KolmogorovSmirnov test confirmed normality of distribution of all but one outcome variable: GHQ. However, given the general robustness of the ANOVA to breaches of the assumption of normality and the value of applying a consistent method across measures we applied the ANCOVA model described above to these outcomes. Given the preliminary nature of the study and limited statistical power, in addition to significance tests, we present standard effect size indicators interpreted as per Cohen's definition of small (0.3), medium (0.5) and large (0.7) effects [6] along with their significance. As there was no differential effect of time (i.e., change between $\mathrm{T} 2$ and $\mathrm{T} 3$ ) for the two groups these were calculated for the mean T2 and T3 score using the standard formulae for Cohen's $d$ (mean of NFPP minus mean of TAU divided by the pooled standard deviation). In order to control for baseline levels residual scores (after regressing $\mathrm{T} 1$ on to T2/T3) were used as measure of treatment effect. In order to take into account the high degree of drop out during the study we undertook a secondary analysis comparing treatment success and failure. In this analysis, all drop outs were allocated to the treatment failure arm, while treatment success was judged against a threshold for clinical change of a decrease in PACS ADHD symptoms of five points. This figure was derived from the clinical change analysis presented in the 2001 trial [30] using the Jacobson and Truax [15]. It represents a reduction of ADHD symptoms to beyond the mid-point between the ADHD and control group. For simplicity of application the figure was rounded to the nearest integer. It is equivalent to approximately a 0.8 of a standard deviation reduction in symptoms in the current study. Given the inclusion of the non-responders in the treatment failure group this provides a very conservative notion of the degree of clinically meaningful change associated with the revised NFPP.

\section{Results}

Treatment drop out

Twenty-one children were randomized to the revised NFPP and 20 to TAU. Two families did not complete the 8-week 
therapy program. Ten families did not complete T2 assessments-four in NFPP including two that did not complete the intervention and six TAU families. Nine families did not complete T3 measures-two NFPP and seven TAU families. Two NFFP participants not assessed at $\mathrm{T} 2$ were assessed at $\mathrm{T} 3$. This meant that $\mathrm{T} 1$ to $\mathrm{T} 3$ data were unavailable for 11 children (four treatment and seven controls). Table 1 reports the child and parent symptom profiles of those children who remained in the study throughout and those that dropped out or did not have measures at all three time points. Drop outs had more severe ADHD as measured by both clinical interview and parent completed questionnaire. They were similar in other respects.

The NFPP and TAU groups did not differ in terms of age $[t(39)=-1.00 ; P=0.322]$ or gender $\left(\chi^{2}(1)=0.01\right.$; $P=0.929)$. The mean and SDs for each outcome measure (T1 to T3) are presented for TAU and NFPP in Table 2 alongside the outcome of the statistical analysis in terms of significance and size of effects. There are significant and very large effects of the treatment on ADHD behaviors and symptoms reported by parents (average $d=1.92$ ) with smaller effects for more general social and behavior problems (average $d=0.71$ ) on parental questionnaire and interview. These effects did not change significantly as a function of time. However, there was a trend toward an interaction for WWP. This appeared to be due more to a drop in scores in ADHD levels between T2 and $\mathrm{T} 3$ in the TAU group than an increase in the NFPP group. Mothers in the treatment group had higher ADHD scores than those in the TAU group. However, including age, gender and parental ADHD symptoms as covariates in the analysis did not alter the intervention effect

Table 1 A comparison of children who remained in and dropped out of the trial

\begin{tabular}{lcclr}
\hline \multicolumn{1}{l}{ In } & Drop outs & $t$ & \multicolumn{1}{l}{$P$} \\
\hline Child age & $51.20(11.30)$ & $47.72(16.33)$ & 0.78 & 0.441 \\
Child symptoms & & & \\
ADHD & & & & \\
PACS & $17.37(5.91)$ & $23.36(6.42)$ & 2.81 & 0.008 \\
WWP & $31.07(7.25)$ & $43.00(7.25)$ & 4.39 & $<0.001$ \\
ODD & & & & \\
PACS & $20.43(7.99)$ & $25.45(7.73)$ & 1.80 & 0.081 \\
BCL & $5.54(1.28)$ & $5.10(1.64)$ & 0.97 & 0.336 \\
Mother symptoms & & & \\
ADHD & $13.77(9.60)$ & $17.70(9.21)$ & 1.13 & 0.265 \\
Depression & $4.12(3.21)$ & $4.30(3.97)$ & 0.14 & 0.887 \\
\hline
\end{tabular}

$A D H D$ attention deficit/hyperactivity disorder, $P A C S$ parental account of childhood symptoms, WWP Werry-Weiss-Peters Scale, $O D D$ oppositional defiant disorder, $B C L$ behavior checklist
$\left(F^{\mathrm{PACS}-\mathrm{ADHD}}(1,23)=12.05 ; \quad P=0.002 ; \quad F^{\mathrm{WWP}}(1,19)=\right.$ 38.94; $\left.P<0.001 ; F^{\text {PACS-CD }}(1,19)=6.32 ; P=0.019\right)$.

Parental psychopathology was not improved by NFPP. There were effects on treatment of parental comments as a component of EE. This was significant for negative comments with a trend for positive comments. Furthermore, the effect of treatment on positive comments was not stable over time as indicated by the treatment by time interaction. This was due to a substantial drop in positive comments between T2 and T3 in the NFPP group. There were no effects on either child or maternal GIPCI scores. Although it fell considerably short of significance there was a moderate sized effect on the observational measure of activity derived from the solo play episode with the child alone $(d=0.55)$. When NFPP and TAU was compared in terms responders versus non-responders using the criteria described above (i.e., including drop outs as non-responders) $40 \%(N=8)$ of those in the NFPP condition compared to $5 \%$ in the TAU $(N=1)$ showed clinical significant reductions in $\mathrm{ADHD}$ symptoms on the $\operatorname{PACS}\left(\chi^{2}(1)=\right.$ 7.025; $P=0.008)$.

\section{Discussion}

Although this was a trial with a small sample size it provides initial support for the potential value of the revised NFPP as a specialized treatment for ADHD and highlights the value of early intervention approaches for the psychosocial treatment of ADHD. The initial trial with the original version of the NFPP [30] demonstrated a medium to large effect size for the reduction of ADHD symptoms in the preschool-age children in the NFPP arm of the study for both observed ADHD behavior in the child $(d=0.69)$ and parental interview/questionnaire of ADHD symptoms ( $d=0.87$ ). In enhancing the program we had hoped to target more effectively the impairments underpinning ADHD by adding novel components. For instance, specific and systematic exposure of children by their parents in the everyday home setting to self-regulation training designed to increase their attention and concentration and reduce their intolerance for delay (as well as other things) was added both in terms of 'formal' games and informal teachable moments. The effect sizes reported in this smallscale trial are on the whole unusually large for a nonpharmacological treatment and are encouraging. The exception to this is the treatment-related change in the direct observation of child behavior. The failure to find effects on this more objective measure of symptom change may indicate that effects were limited to subjective elements of assessment tied to parental perceptions. Alternatively it may reflect the lower levels of reliability of this measure. Obviously these initial results need to be 


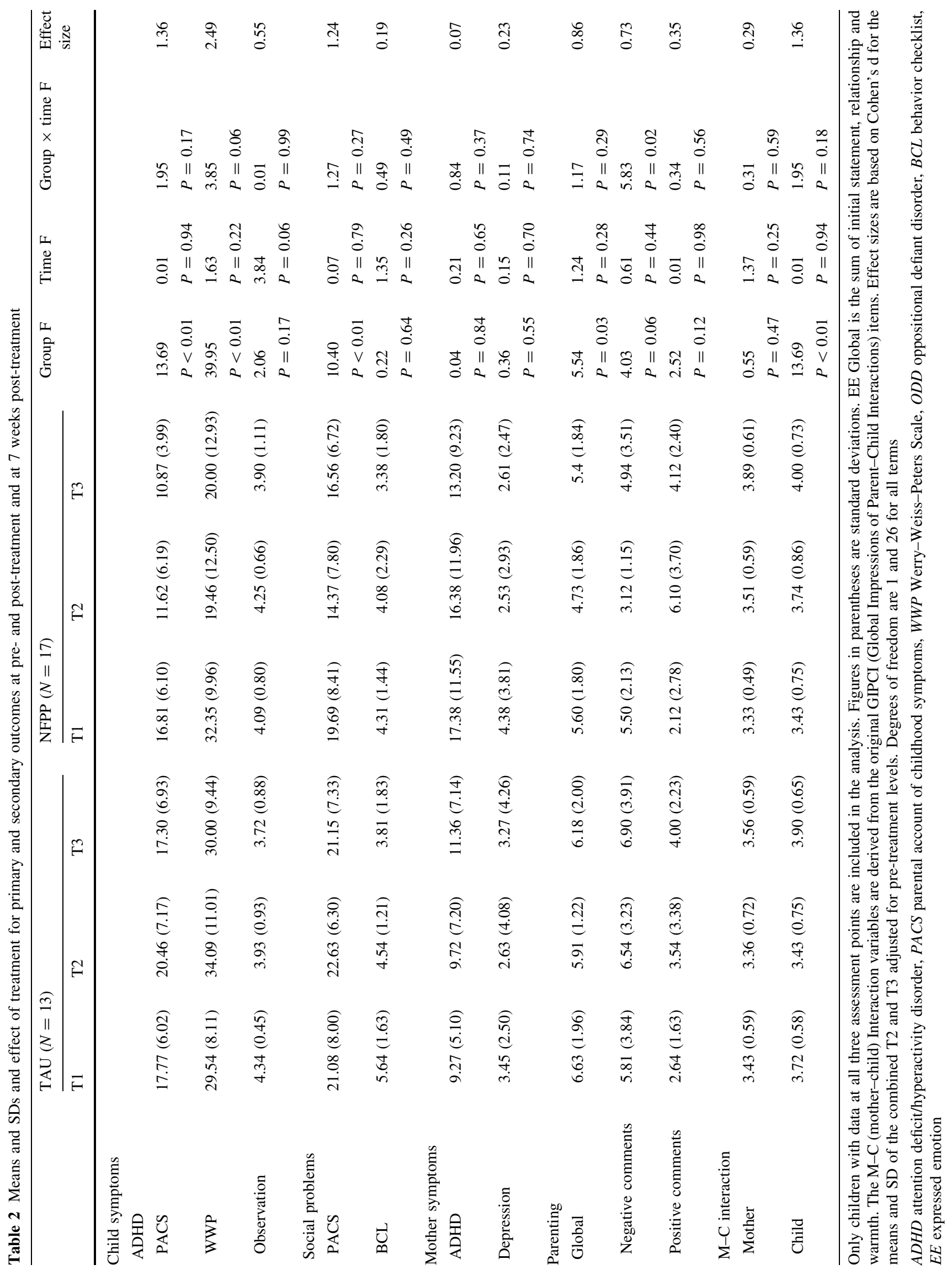


replicated in a much larger trial and with an intention to treat analysis. Such a study is ongoing. The results, which were maintained during an 8 -week post-treatment followup period, suggest that it may be possible and valuable to target core deficits using parenting approaches.

As far as the secondary impact of the NFPP on more general social and behavior problems is concerned, the effect size found for the PACS interview measure is encouraging, although these effects did not extend to the BCL social problem scale. The reason for this is unclear. The effects on PACS ODD could have a number of origins. They could be a knock-on effect of the larger reductions in ADHD. They could also be a more direct effect of elements of the parenting program. Along with standard behavioral techniques for reducing oppositional and non-compliant behavior, the NFPP has a strong emphasis on authoritative communication and the development of strategies used for enabling positive co-operation between parent and child thus encouraging self-regulation and the reduction of temper tantrums and oppositional behavior. The current trial was not designed to distinguish between these direct and indirect effects. Nevertheless, there was a reduction in negative comments and an increase in positive comments in EE. This factor could have mediated the effects of NFPP on oppositional behaviors. We did not have the statistical power to test this in the current study. Given the EE effects it was somewhat surprising that there were no significant effects on the quality of mother-child interaction as measured by the GIPCI. This was unexpected as the NFPP targeted the parent-child relationship and thus it remains unclear what factors may mediate the effects of the treatment on ADHD. One possibility is that the components of parenting assessed by the GIPCI did not capture the changes in parenting brought about by the package. Assessment in future trials should perhaps include outcomes linked more closely to the specific parenting behaviors targeted by the NFPP.

The original NFPP trial showed benefits in terms of mothers' mental health; this was not the case in the current trial. Many of the mothers had symptoms of ADHD themselves and also symptoms of depression which make for inconsistent parenting and inability to cope with children's oppositional style [28]. The therapists were trained to take these features into account; for example, they paced the program if the nurse thought the mothers were depressed and needed strategies to be repeated at the next session. If the mother herself was thought to have ADHD, time was spent suggesting strategies to the mother to deal with her own ADHD in order to help the child, for example by organizing her life so that she had time to organize the child. The child's behavior improved despite these symptoms which is encouraging (although the mothers' symptoms of ADHD did not change, and although the mother's changes in symptoms of depression did reduce below "caseness", the change was not statistically significant).

The current trial has a number of limitations. First, the small sample size limited the ability to demonstrate statistical significance for all but the largest effect sizes. Second, there was a substantial degree of drop out during the trial. Furthermore, those children dropping out had higher levels of ADHD and oppositional defiant scores than those remaining in the trial. However, the fact that drop outs were more common in the TAU group suggests that children with higher ADHD at T1 remained in the NFPP group. Third, for practical reasons the follow-up period was only 8 weeks which meant there was only limited scope for assessing treatment maintenance. Fourth, we did not evaluate child outcomes in school settings so had no independent evaluation of change in ADHD symptoms other than the observation of the child. Fifth, the standardized clinical entry criteria for the study did not incorporate direct observation of the child as a source of information.

In summary, the GAPP study provides preliminary support for the feasibility and potential efficacy of the revised NFPP with very marked effects on ADHD and smaller, although significant effects of ODD and some parenting factors.

Acknowledgments The project was funded by The Island of Guernsey Research Fund through Wessex Medical Trust HOPE to MT, ES-B, LP, PT. We would like to thank the health visitors and other health staff on the Island of Guernsey for supporting our project and the help we were given from the press of Guernsey for promoting the project. Lastly we would like to thank all the families who took part.

\section{References}

1. Barkley R, Murphy K (1998) Attention deficit hyperactivity disorder: a clinical workbook. The Guilford Press, New York

2. Bor W, Sanders MR, Markie-Dadds C (2002) The effects of the Triple P-Positive Parenting Program on preschool children with co-occurring disruptive behavior and attentional/hyperactive difficulties. J Abnorm Child Psychol 30:571-587

3. Brotman LM, Gouley KK, Chesir-Teran D, Dennis T, Klein RG, Shrout P (2005) Prevention for preschoolers at high risk for conduct problems: immediate outcomes on parenting practices and child social competence. J Clinic Child Adolesc Psychol 34:724-734

4. Brotman LM, Calzada E, Dawson-McClure S: GIPCI-R unpublished manuscript. New York University

5. Christiansen H, Chen W, Oades R, Asherson P, Taylor E et al (2008) Co-transmission of conduct problems with attention-deficit/hyperactivity disorder: familial evidence for a distinct disorder. J Neural Transm 115:163-175

6. Cohen J (1988) Statistical power analysis for the behavioral sciences. Lawrence Erlbaum Associates, Hillsdale

7. Conners CK, Epstein JN, March JS, Angold A, Wells KC, Klaric J, Swanson JM, Arnold LE, Abikoff HB, Elliott GR, Greenhill LL, Hechtman L, Hinshaw SP, Hoza B, Jensen PS, Kraemer HC, Newcorn JH, Pelham WE, Severe JB, Vitiello B, Wigal T (2001) 
Multimodal treatment of ADHD in the MTA: an alternative outcome analysis. J Am Acad Child Adolesc Psychiatry 40:159167

8. Daley D, Sonuga-Barke EJS, Thompson M (2003) Assessing expressed emotion in mothers of preschool $\mathrm{AD} / \mathrm{HD}$ children: psychometric properties of a modified speech sample. Br J Clin Psychol 42:53-67

9. Daley D, Jones K, Hutchings J, Thompson M (2009) Attention deficit hyperactivity disorder in preschool children: current findings, recommended interventions and future directions. Child Care Health Dev (in press)

10. Egger HL, Kondo D, Angold A (2006) The epidemiology and diagnostic issues in preschool attention-deficit/hyperactivity disorder-a review. Infants Young Child 19:109-122

11. Goldberg D (1982) General health questionnaire manual. NFER, Windsor

12. Greenhill L, Kollins S, Abikoff H, McCracken J, Riddle M, Swanson J, McGough J, Wigal S, Wigal T, Vitiello B, Skrobala A, Posner K, Ghuman J, Cunningham C, Davies M, Chuang S, Cooper T (2006) Efficacy and safety of immediate-release methylphenidate treatment for preschoolers with hyperactivity. J Am Acad Child Adolesc Psychiatry 45:1284-1293

13. Hardy G, Shapiro D, Haynes C, Rick J (1999) Validation of the general health questionnaire-12 using a sample of employees from England's health care services. Psychol Assess 11:159-165

14. Hinshaw SP, Klein R, Abikoff H (2002) Nonpharmacologic treatments and their combination with medication. In: Nathan PE, Gorman J (eds) A guide to treatments that work, 2nd edn. Oxford University Press, New York, pp 3-23

15. Jacobson NS, Truax P (1991) Clinical-significance-a statistical approach to defining meaningful change in psychotherapyresearch. J Cons Clin Psychol 59:12-19

16. Jensen PS, Arnold LE, Richters JE, Severe JB, Vereen D, Vitiello B, Schiller E, Hinshaw SP, Elliott RG, Conners CK, Wells KC, March J, Swanson J, Wigal T, Cantwell DP, Abikoff HB, Hechtman L, Greenhill LL, Newcorn JH, Pelham WE, Hoza B, Kraemer HC (1999) A 14-month randomized clinical trial of treatment strategies for attention-deficit/hyperactivity disorder. Arch Gen Psychiatry 56:1073-1086

17. Jones J, Daley D, Hutchings J, Bywater T, Eames C (2007) Efficacy of the incredible years basic parent training programme as an early intervention for children with conduct problems and ADHD. Child Care Health Dev 33:749-756

18. Kochanska G, Murray KT (2000) Mother-child mutually responsive orientation and conscience development: from toddler to early school age. Child Dev 71:417-431

19. Kollins S, Greenhill L, Swanson J, Wigal S, Abikoff H, McCracken J, Riddle M, McGough J, Vitiello B, Wigal T, Skrobala A, Posner K, Ghuman J, Davies M, Cunningham C, Bauzo A (2006) A rationale, design and methods of the preschool ADHD treatment study (PATS). J Am Acad Child Adolesc Psychiatry 45:1275-1283

20. Murphy K, Barkley R (1996) Attention deficit hyperactivity disorder in adults: comorbidities and adaptive impairments. Compr Psychiatry 37:393-401

21. Nowak C, Heinrichs N (2008) A comprehensive meta-analysis of triple p-positive parenting program using hierarchical linear modelling: effectiveness and moderating variables. Clin Child Fam Psychol Rev 11:114-144

22. Piccinelli M, Bisoffi G, Bon M, Cunico L, Tansella M (1993) Validity and test-retest reliability of the Italian version of the 12item general health questionnaire in general practice: a comparison between three scoring methods. Comp Psychiatry 34:198205

23. Psychogiou L, Daley D, Thompson M, Sonuga-Barke E (2008) Do maternal attention-deficit/hyperactivity disorder symptoms exacerbate or ameliorate the negative effect of child attentiondeficit/hyperactivity disorder symptoms on parenting? Dev Psychopathol 20:121-137

24. Richman N (1977) Is a behaviour check list for preschool children useful? In: Graham PJ (ed) Epidemiological approaches to child psychiatry. Academic Press, London, pp 125-136

25. Rogers SJ (2000) Interventions that facilitate socialization in children with autism. J Autism Dev Disord 30:399-409

26. Routh D (1978) Hyperactivity. In: Magrab P (ed) Psychological management of paediatric problems, 2nd edn. University Park Press, Baltimore

27. Sonuga-Barke EJS, Thompson M, Daley D, Laver-Bradbury C (2004) Parent training for attention deficit/hyperactivity disorder: is it as effective when delivered as routine rather than as specialist care? Br J Clin Psychol 43:449-457

28. Sonuga-Barke E, Daley D, Thompson M (2002) Does maternal $\mathrm{AD} / \mathrm{HD}$ reduce the effectiveness of parent training for pre-school children's AD/HD? J Am Acad Child Adolesc Psychiatry 41:696-702

29. Sonuga-Barke EJS, Thompson M, Stevenson J, Viney D (1997) Patterns of behaviour problems among pre-school children. Psychol Med 27:909-918

30. Sonuga-Barke EJS, Daley D, Thompson M, Laver-Bradbury C, Weeks A (2001) Parent-based therapies for preschool attentiondeficit/hyperactivity disorder: a randomized, controlled trial with a community sample. J Am Acad Child Adolesc Psychiatry 40:402-408

31. Sonuga-Barke EJS, Sergeant J, Nigg J, Willcutt E (2008) executive dysfunction and delay aversion in attention deficit hyperactivity disorder: nosological and diagnostic implications. Child Adolesc Psychiatryic Clin North Am 17:367-384

32. Sonuga-Barke EJS, Thompson M, Abikoff H, Miller Brotman L, Klein R (2006) Non-pharmacological interventions for preschool ADHD: the case for specialized parent training. Infants Young Child 19:142-153

33. Sonuga-Barke EJS, Lamparelli M, Stevenson J, Thompson M, Henry A (1994) Pre-school behaviour problems and intellectual attainment; the associations of hyperactivity and conduct problems. J Child Psychol Psychiatry 35:949-960

34. Swanson JM, McBurnett K, Wigal T, Pfiffner LA, Lerner MA, Williams L, Christian DL, Tattina L, Willicutt E, Crowley K, Clevenger W, Khounzana N, Woo C, Crinella F, Fisher TD (1993) Effect of stimulant medication on children with attentiondeficit disorder: a review of reviews. Except Child 60:154-162

35. Taylor EA, Sandberg S, Thorley G, Giles S (1991) The epidemiology of childhood hyperactivity. Institute of Psychiatry Maudsley Monographs, Oxford University Press, London

36. Thompson MJJ, Stevenson J, Sonuga-Barke E, Nott P, Bhatti Z, Price A, Hodswell M (1996) The mental health of pre-school children and their mothers in a mixed urban/rural population. 1. Prevalence and ecological factors. Br J Psychiatry 168:16-20

37. van den Hoofdakker BJ, Van der Veen-Mulders L, Sytema S, Emmelkamp PMG, Minderaa RB, Nauta MH (2007) Effectiveness of behavioral parent training for children with ADHD in routine clinical practice: a randomized controlled study. J Am Acad Child Adolesc Psychiatry 46:1263-1271

38. van der Oord S, Prins PJM, Oosterlaan J, Emmelkarnp PMG (2007) Does brief, clinically based, intensive multimodal behaviour therapy enhance the effects of methylphenidate in children with ADHD? Eur Child Adolesc Psychiatry 16:48-57

39. Webster-Stratton C, Reid MJ, Stoolmiller M (2008) Preventing conduct problems and improving school readiness: evaluation of the incredible years teacher and child training programs in highrisk schools. J Child Psychol Psychiatry 49:471-488

40. Wigal T, Greenhill L, Chuang S, McGough J, Vitiello B, Skrobala A, Swanson J, Wigal S, Abikoff H, Kollins S, McCracken J, 
Riddle M, Posner K, Ghuman J, Davies M, Thorp B, Stehli A (2006) Safety and tolerability of methylphenidate in preschool children with ADHD. J Am Acad Child Adolesc Psychiatry 45:1294-1303
41. Zito JM, Safer DJ, Dosreis S, Gardner JF, Boles M, Lynch F (2000) Trends in the prescribing of psychotropic medications to preschoolers. J Am Med Assoc 23:1025-1030 